\title{
Developing Culturally Responsive Curriculum and Learning Resources for School Library Education Programs
}

\author{
Pamela Louderback \\ Northeastern State University, USA
}

\begin{abstract}
This article provides a reflective examination, using a case study as a teaching and learning strategy to develop intercultural competence and improve academic learner performance. Guided by the social constructivism paradigm, critical race theory (CRT) was used as a theoretical framework. After receiving an Institute for Museum and Library Services (IMLS) Laura Bush 21st Century Librarian Program grant, one Oklahoma institution provided distributed, community-based instruction to rural areas and fostered a community of practice to support pre-service school library teachers. This article presents approaches and assessments based on the program that incorporated a culturally responsive pedagogy in its specialized curriculum and created information literacy resources to improve student success in racially diverse and economically disadvantaged schools and communities. The article further reviews factors that influenced learning and teaching in this program. Significant contributions include the creation of a unique program that provides a framework for practicing professionals in K-12. Curriculum, resources, and information literacy tools are made available to help sustain educational efforts for those who serve in similar communities. The planning, design, development and distribution of digital format information literacy modules address education-based needs to enhance information literacy skills, to incorporate "faces of diversity" that help targeted viewers personally relate more positively to the learning experience, and to deliver current "standards based" training resources. Lesson plans and learning resources created during and after the program can continue to provide opportunities for cross-cultural dialogue between Indigenous and Non-Indigenous educators in shared study, mentoring, and faculty/teacher training.
\end{abstract}

\section{Introduction}

Intercultural competence has become a valuable asset in the global community. It enables students to enhance critical thing and personal development from a more culturally competent perspective. Programs that support inter-culturally competent pieces create opportunities for student to engage with other societies, and to develop tolerance and understanding of diverse cultural traditions and practices. Program curriculum modifications ] supported by data and research regarding best practices for inclusive educational practices were established in a teacher education program at Northeastern State University (NSU) a comprehensive regional university and the fourthlargest public four-year institution of higher learning in Oklahoma. It is the oldest institution of higher learning in the state of Oklahoma as well as one of the oldest institutions of higher learning west of the Mississippi River. Founded as the Cherokee National Female Seminary in 1846, the university has historic links to the Cherokee Nation and Indian Territory. The main campus is located in Tahlequah, home to the capital of the Cherokee Nation of Oklahoma. The university has many courses focused on Native American linguistics, and offers Cherokee language Education as a major. Cherokee can be studied as a second language, and some classes are taught in Cherokee for first language speakers as well. Almost 29 percent of NSU's student population are selfidentified American Indians, and each year the institution graduates the highest number of American Indians among public four-year institutions nationwide.

Cultural awareness and competency development in higher education is essential in the development of students' global competence. Focusing on administration and faculty implementation of culturally-aware curriculum to support that development is critical to address as the student population continues to grow in diversity. To ensure students develop the cultural competence to adapt to new environments, developing policies and programs that aid in the progression of cultural acceptance and understanding is key. Based on these factors of multiculturalism, and recognizing the need to include a formal culturally responsive program, it was determined that the university could serve as a useful case study for a culturally responsive indigenous instruction program in teacher education. The university applied for and was awarded a grant from the Institute of Museum and Library Services (IMLS) under the Laura Bush 21st Century Librarian Program, Category 5 to educate school librarians and develop specialized curriculum and information literacy resources to improve student success in racially diverse and economically disadvantaged schools and communities in northeast Oklahoma. The university graduate program in Library Media and Information Technology, the university College 
of Education, and the University Libraries, in cooperation with the Cherokee Nation, the Oklahoma Department of Libraries, the Oklahoma State Regents for Higher Education and select Oklahoma school districts in northeast Oklahoma partnered to create an innovative program committed to helping cover issues of diversity and inclusion.

The program was formed to educate and develop information literacy resources for school librarians who serve in rural communities with high percentages of Native American populations including rural areas with high poverty levels. Major issues teachers face involved outdated teaching practices and lack of basic content knowledge, as well as illiteracy and language barrier challenges that consistently resulted in poor academic performance [1]. There is the need for teachers who are able to effectively respond to the diverse needs and learning styles of their students. Along with knowledge of subject matter, teachers must also have an understanding of learners and their social context in order to help them succeed, as noted in DarlingHammond and Baratz-Snowden's theoretical framework for learning to teach [2]. Teachers must also be able to assess their own beliefs, values, and potential biases that they may bring to the classroom.

Prospective teachers should have cultural awareness and competency to know how to successfully perform in response to the changing social dynamics in schools. These challenges necessitated a need to come up with interactive teaching and learning strategies. Guided by the social constructivism paradigm and using critical race theory (CRT) as a theoretical framework that places race at the center of educational research and discourse, we provide conditions for the successful implementation of the case study as a teaching and learning strategy for culturally responsive, inclusive education that may help develop and advance academic learner performance for indigenous students. The conceptual framework of social constructivism was applied to understand the use of case study as a teaching and learning strategy for improved academic learner performance. This framework was adopted because it helps learners construct knowledge, based on their own experiences, in an active process facilitated by a teacher, rather than being lectured about predetermined knowledge [3]. Knowledge construction has the potential to encourage teaching, and views of school learning that are dynamic, interactive, and expanding rather than static and prescribed. It is strongly believed that positive teaching and learning can be ensured if learners are given an opportunity to apply the existing body of knowledge in a manner that they are able to make sense out of concepts or socio-economic issues. Using the social constructivism approach as a conceptual framework enabled learners to become conscious of their own learning and to better develop their understanding of the teaching practices they experience. In this way, they were able to purposefully link the manner in which they learn in a given situation with the nature of the teaching itself [4]. The program provided a comprehensive, inclusive and holistic approach to educating school librarians to promote and perform positive educational change which included the integration of information literacy into the curriculum in their training and instruction. This program educated new school librarians in critical competencies, and provided the profession with targeted K-12 curriculum, resources, and information literacy tools to sustain the efforts of all school librarians who serve in similar diverse communities.

\section{Positive Educational Change through Culturally Relevant Curricula}

Quality education is the key to success in improving long term economic, cultural, and social factors in these communities. School librarians play a uniquely critical role in K-12 students' academic success. Further, we believe that school librarians can dramatically improve educational effectiveness at their institutions when they are specifically trained and equipped to meet the critical needs of their unique student populations.

The core objective of this program was to provide a comprehensive and holistic approach to educating school librarians to promote and perform positive educational change. The unfortunate forced relocation of Native American populations to Oklahoma territory in the 1800's helped create deep cultural, social, and economic divides that have resulted in dramatic negative economic and educational consequences that manifest to this day. These negative economic and educational consequences are well documented and evidenced today through the high levels of family poverty and excessive Native American dropout rates in the communities we serve. Poverty rates in the targeted counties in northeast Oklahoma have a direct negative impact on student success. Additionally, according to a report published by the Annie E. Casey Foundation, entitled KIDS COUNT Data Center, http://datacenter.kidscount.org/, eight counties in the targeted Oklahoma counties exhibited child poverty rates in excess of $30 \%$ for children under the age of 18 . The evidence shows that high achieving schools and related human capital investment strategies are key ingredients in promoting sustainable development. 


\subsection{Primary Goals}

It was the intent of the program to provide sufficient institutional capacity to cooperatively attain two primary goals by completing four critical outcomes. The first primary goal was to train $21 \mathrm{st}$ century school librarians to meet the unique needs of the targeted communities. NSU has a proud tradition of successfully serving Native American populations since it was founded as a Cherokee seminary in the Tahlequah, Oklahoma area over 100 years ago. Today, the student population of NSU has the highest percentage (just under 30\%) of Native American students of any public higher education institution in the United States, as published in The Winds of Change Annual College Guide, 2008. As such, NSU is uniquely positioned to be the leader in educating school librarians to meet the evolving needs of students in the 21st Century. The second primary goal was to develop and provide information literacy programming and digital learning resources to assist in improving and sustaining $\mathrm{K}-12$ pedagogy that effectively increase targeted student success. This goal will be further addressed under section five.

\subsection{Culturally Responsive Teaching Theory}

Culturally relevant teaching, defined as one "that empowers students to maintain cultural integrity, while succeeding academically", was made popular by Dr. Gloria Ladson-Billings in the early 1990s. [5]. Cultural difference theorists concerned about the disparities in academic achievement between mainstream student and those marginalized within the schools and the larger society include Kathryn $\mathrm{H}$. $\mathrm{Au}$ [6], Gloria Ladson-Billings [7, Lisa Delpit [8], Jacqueline Jordan Irvine [9], Luis Moll [10], and Sonia Niero [11] who constructed a theory of culturally responsive teaching also termed "culturally sensitive" pedagogy. By applying these theories, educators may help to improve academic achievement of students from diverse racial, ethnic, cultural, linguistic, and social-class groups. Studies have demonstrated that both reading achievement and reading motivation are affected by the availability of literature that offers children "personal stories, a view of their cultural surroundings, and insight on themselves" [12]. For children of color. this means providing culturally relevant multicultural literature materials for comprehension and recall [13]. Research further shows that with repeated exposure to engaging literature in which children of color find characters and a context that they can recognize and to which they can relate, reading is more likely be an appealing and successful activity [14]. It is further postulated that academic achievement of these students will increase if schools and teachers reflect and draw on their cultural and language strengths when integrating information literacy into their curriculum [15]. One key educational researcher who has contributed significantly to the progression of culturally relevant teaching is Geneva Gay. In her landmark book, Culturally Responsive Teaching: Theory, Research, and Practice (2010), the author expanded the traditional view of culture beyond race and ethnicity. She wrote, "Even without being consciously aware of it, culture determines how we think, believe, and behave". The teacher who practices culturally relevant teaching recognizes that culture manifests in a range of adaptations that demonstrate how students prefer to learn. A culturally responsive teacher uses differentiated instruction to tailor learning for every aspect of a student's culture. Many of these researchers and educators support the constructivist theories of education because such perspectives recognize the value of multiple cultural viewpoints [16].

Despite the steadily increasing numbers of culturally and linguistically diverse student populations in schools, not all teacher education programs readily embrace multicultural education or culturally responsive teacher education pedagogy. A major part of the resistance comes from teacher educators' discomfort, if not fear of, addressing issues such as race and racism in their courses, or even on their campuses according to Cochran-Smith [17]. It is from this perspective that our institution created a distributed critical, community-based culturally responsive instruction that fostered a community of practice and support of pre-service school librarians in the program.

\section{Holistic Methodology of Inclusive Education}

The planning, design, development and distribution of digital format information literacy modules in this program addressed three identified education-based needs: low information literacy skill acquisition, lack of "faces of diversity" in learning modules, and "standards based" information literacy training resources. According to the American Association of School Librarians (AASL), school libraries in the 21 st century will depend upon librarians who are well versed in information technology and the ever-expanding role of information in our society. As noted in Empowering Learners: Guidelines for School Library Media Programs:

"The focus has moved from the library as a confined place to one with fluid boundaries that is layered by diverse needs and influenced by an interactive global community. Guiding principles for school library media programs must focus on building a flexible learning environment with the goal of producing successful learners skilled in multiple literacies." [18]. 
Data from a project of the Oklahoma Library Skills Initiative (2009) demonstrated that freshmen students in Oklahoma have significantly lower information literacy skills than comparable freshmen students at similar institutions nationwide. This project created socially and culturally based literacy products that allowed school librarians to better serve their diverse communities. These new tools more effectively fulfilled patron information needs because they were based on the unique use of literacy and language choice from a cultural context. The project also advanced the state of the art of library and information science by providing school library media specialists with critically needed digital instructional tools to assist in teaching information literacy concepts to K-12 students.

\subsection{Incorporating an Online Education Program to Addressing Student Challenges}

A major obstacle to pursuing advanced education in northeast Oklahoma is the distance graduate students currently are required to travel to attend class. A specific challenge in areas of the United States exists in the students' ability to physically access institutions of higher education [19]. Most universities are located in urban and suburban regions, and students who live in rural communities often have difficulty driving long distances to attend classes in person on a university campus. Students who are able to attend evening courses often leave work early to drive several hours to campus, attend class, and then drive hours back to their home communities. Online education mitigates those challenge of traveling for students in rural areas of the country. However, rural areas often lack dependable Internet service; few households are able to access high-speed services commonly available in urban and suburban areas. Students who may wish to participate in online learning experiences often must contend with unreliable Internet access. This scenario represents the experiences of many of our institutions' students.

The grant provided local hub-site instructional locations, distance education equipment, and technology and curricular resources and materials for students in this specialized cohort. Courses were synchronously and asynchronously delivered in a hybrid distance education format, utilizing state-ofthe-art videoconferencing, group meetings, and individual work on Blackboard. Knowledge transfer was fostered using Blackboard Collaborate to create cultural connections using a delivery method that was both exciting and engaging. The learning management system offered tools to create content, the ability to discover, author, and share open educational resources and seamless integration with high-quality, education content from a major elearning digital content. "Digital native" learners bring a new set of expectations about where and how they can access and engage with course materials, instructors, and even each other. One of the key ways the power of technology was harnessed in the classroom was through the integration of digital content via the learning management system.

This model educational program empowered learners to be critical thinkers, skillful researchers and ethical users of information by integrating culturally sensitive evidence-based learning projects and information literacy projects to build more practical experience into classroom instruction. The use of Blackboard technology solved the challenges of off campus learning. By creating local instructional sites, the schools benefited by receiving additional distance education equipment, and candidates met together in small groups and develop supportive networks and communities of practice. Wenger [20] defines a community of practice as a group of individuals who meet together for the purpose of learning from one another, to share experiences, solutions to common or shared problems, and to find areas for coordination and cooperation. The small groups allowed students to have peer face-to-face communication and avoid prolonged isolation of the individual members.

As student candidates were identified for participation in the project, the selection of geographically convenient hubs became a necessary component of the overall plan. Additionally, areas with high percentages of Native K-12 student populations were selected. Because of the rural nature of the communities and the lack of widespread Internet access in some areas, public school sites served as remote instructional sites. District administrators and building principals were contacted to discuss the possibility of obtaining space in a remote classroom, utilizing the school space after-hours, and equipping the facility with the distance education equipment. Five hub sites were eventually selected and were strategically placed in these rural communities. Many of the student candidates lived and taught in these areas, and had the opportunity to utilize the equipment at other times during their work day. Each of the remote sites were equipped with computers, Smart Boards, video cameras and microphones. At the end of the grant period, each of the schools were able retain the equipment and set up areas dedicated to distance education. This outcome allowed schools to continue to provide education opportunities, higher educational courses and programs, and professional development programming to the five sites.

\subsection{Constructivist Learning Community}

Candidate students in the cohort were comprised of practicing, experienced classroom teachers, current librarians (working on provisional credential 
certificates), and some who were not currently employed within the education sector. This mixture of individuals presented a valuable perspective on the readings, course work, field experiences, and whole group discussions that contributed to a larger and more complete understanding of the issues that face culturally diverse rural communities. Yukawa [21] notes that within the context of a community of practice, "learning is not merely knowledge acquisition but more fundamentally a process of identity formation and empowerment through participation" (p.55). Luna and Medina note that adult learners seek practical, pertinent learning experiences within a supportive environment. By sharing individual experiences, stories from classrooms, struggles in schools, understandings of best teaching practices, and knowledge of students each member was able to contribute their part to a larger whole of understanding and deepen the learning experience of the small group that met together. Small and Palling (cited in Dow, 2008) stress the evidence from their longitudinal research indicating students enrolled in distance education courses found greater satisfaction in the social learning aspect of their studies when there were opportunities to develop interpersonal relationships [22]. These opportunities were central to the delivery of courses and the rationale behind establishing the hub site locations.

Because the learning sites were situated throughout the northeast and southeast regions of the state, learning opportunities and learning materials developed as a part of the courses were created to support the needs of the local schools and students. Following Kazmer's model of community embedded learning, the courses were designed to facilitate community-based instructional change, and students were encouraged to use local school curricula as a basis for inquiry projects and bridge the cultures of home, school, and university [23]. The program faculty members acknowledged constructing "area specific" projects, assignments, and new learning experiences that would be beneficial in positively affecting local schools in the candidates' communities. This type of learning community that is built on shared experience and group knowledge development is a classic example of a constructivist learning community. Constructivist theory advances that students' existing knowledge and life experiences are the components used to construct new knowledge structures as new information is provided. The students are active participants in the learning experience, and the teacher serves as a facilitator of the knowledge construction process [24]. Further, constructivist classrooms are beneficial to adult learners as they value the students' lived experience. Their contribution of those experiences and knowledge are essential to the group and the classroom dynamic [25]. Many researchers and educators who embrace culturally responsive teaching also support the constructivist theories of education because such perspectives recognize the value of multiple cultural viewpoints.

\section{Culturally Responsive Curriculum Development}

In this program, graduate level courses utilized a curriculum that was designed to provide supplemental material that addresses social, economic, and educational improvement issues in rural communities with high poverty rates and high percentages of Native American students. Existing courses in the program were revised to address these social, economic, and educational improvement issues through modified courses that allowed for the instructors to include specialized readings, texts, and activities while remaining consistent with the national standards approved course sequence and major assessments and the guidelines of the institution. Gay's (2010) Culturally Responsive Teaching: Theory, Research, and Practice, 2nd ed., was used as a supplemental text for candidates to become familiar with the practices of culturally responsive teaching and reflective self-assessment as they participate in the directed activities and experiences related to the grant. Student candidates assessed their current teaching practices through reflective journaling and discussion board posts based on the Gay text.

Throughout the program, courses were modified slightly to address the objectives of the grant. Students reflected on the grant objectives through the use of Native specific databases and multicultural videos available through a variety of sources. Selected collections of books by and about Native peoples were researched, vetted, and included for candidates to review and discuss. This process allowed the candidates to immerse themselves in readings on the topic of multiculturalism. In the resource selection courses, candidates evaluated materials based upon issues of multicultural awareness. They used evidence from articles, their own experiences, and professional thoughts to reinforce responses by composing reflective journal entries throughout their coursework. In addition to these resources and curriculum provided to the student candidates, they were given assignments where they created a number of resources that could be used and enjoyed by K-12 students. One example included bibliographies of selected materials to be shared with tribal partners that might assist in the development of area tribal school libraries. In qualitative research classes, candidates conducted action research in the targeted communities to help broaden the professions' understanding of the factors that impact student success in the targeted communities. Two courses provided the student 
candidates with additional literacy and reading terms, habits and tools needed to assess children's literature and library materials for a multicultural student population. Candidates used a variety of strategies to promote leisure reading. Candidate students also modeled their personal enjoyment of reading in order to promote the habits of creative expression and lifelong reading through a teen culture project.

Candidates used young adult books representing Native cultures for book discussion assignments with K-12 students. Students located at the hub site areas were employed as participants in the book discussions. As well, Native students from area schools (Sequoyah High School, Oaks Indian School) participated in book discussion groups. Representative titles used for book discussion events included those written by well-known Native authors such as Joseph Bruchac, Cynthia Leitch-Smith, Joseph Medicine Crow, Marlene Carvell, Robert J. Conley, Victoria McKernan, and Sherman Alexie. Another course assignment involved reading a poetry chapter that highlighted Native poetry books. Titles used for the poetry assignment included: Spirit Voices of Bones, Rising Voices, The Book of Medicines, and No Borders. All candidates read the following titles: Absolutely True Diary of a PartTime Indian by Sherman Alexie for contemporary fiction and censorship; Pipestone, My Life in an Indian Boarding School by Adam Fortunate Eagle (Kindle version), for non-fiction, and Sitting Bull by Kate Petty for the graphic novel format. Journal articles and critical essays examined included: "Humor Is My Green Card": A Conversation with Sherman Alexie; Alexie-Vision: Getting the Picture by Susan Bernardin; Absolutely True Tales of Censorship; and "I knew how to be moderate. And I knew how to obey": and The commonality of American Indian boarding school experiences, 1750s-1920s by Margaret Connell Szasz.

Prospective educators vary greatly in their knowledge and skills before they enter pre-service teacher programs. Some are familiar with their content area. Others are familiar with children, curriculum, and child development. Some have years of experience working with children or young adults in settings outside of the school environment. Many prospective educators are well educated but lack the skills and experiences necessary to transform that knowledge into culturally responsive practices that are effective. Others possess knowledge relevant to teaching and learning but lack the skills to reach students who learn in different ways. Structuring preservice teacher/librarian education by organizing the curriculum in a scope and sequence that capitalize on teacher development allows prospective teachers to move from a focus on self to a focus on student learning. As well, they are able to move from the foundations of learning theories to their implications for teaching. It also means finding ways for teachers to learn about practice in practice. To insure that concrete applications can be made and problems of practice can be raised, analyzed, and addressed, programs should provide ways for prospective teachers to learn about practice in practice. Curricula and assignments need to provide prospective teachers with consistent opportunities to apply what they are learning, to analyze outcomes, and to adjust their efforts accordingly. In this program, student teachers engaged in inquiry and reflection about learning, teaching, and curriculum using culturally responsive pedagogy. Assignments were integrated into each course to help students illustrate a growing understanding of cultural responsiveness throughout the program.

\section{Culturally Sensitive K-12 Curriculum Resources}

The second primary goal of the program was to develop and provide information literacy programming and digital learning resources to assist in improving and sustaining K-12 pedagogy that effectively increases targeted student success. The planning, design, development and distribution of digital format information literacy modules served to address three identified education-based needs. First, data from a project of the Oklahoma Library Skills Initiative (2009) demonstrated that freshmen students in Oklahoma had significantly lower information literacy skills than comparable freshmen students at similar institutions nationwide. The learning modules created could be used to enhance information literacy skills in K-12 students to better prepare them to complete high school and to attend college. Second, research shows that students are more likely to model behavior of individuals that "look" like them [26]. Modules incorporated "faces of diversity" showing real high school aged students (consultants) in learning/teaching situations that help targeted viewers personally relate more positively to the learning experience.

"In many Native American cultures, children learn new skills by observing them and then doing them. This hands-on technique is part of their natural learning style and should be used to the maximum extent possible. Teachers are realizing more and more that an active, hands-on curriculum benefits all learners and usually leads to a fuller understanding of the concepts represented." [27].

Third, all pre-service teacher/librarian school library programs desperately need additional current "standards based" age appropriate information literacy training resources that can be used to supplement and reinforce instruction efforts that current exist. The products developed in this program could be integrated into the curriculum resources disseminated in specialized program. 


\subsection{Information Literacy Resources}

Research, development, creation, and dissemination of online information literacy instruction modules that address information literacy standards for K-12 instruction and focus on the needs of racially diverse populations served as a major outcome. Learning modules created in the project were used to enhance information literacy skills in $\mathrm{K}-12$ students to better prepare them to complete high school and to attend college. Current "standards based" age appropriate information literacy training resources were developed to supplement and reinforce existing instruction efforts. Existing courses in the Library Media and Information Technology program were revised to address these social, economic, and educational improvement issues through modified courses that allowed for the instructors to include specialized readings, texts, and activities while remaining consistent with the NCATE/ALA/AASL approved course sequence and major assessments and the guidelines of the institution. Selected collections of books by and about Native peoples were researched, vetted, and included for candidates to review and discuss; this allowed the candidate students to immerse themselves in readings on the topic of multiculturalism. In the resource selection courses, candidates evaluated materials based upon issues of multicultural awareness. Students used evidence from articles, their own experiences, and professional thoughts to reinforce their responses by composing reflective journal entries throughout the program. In addition to these resources and curriculum provided to the cohort candidate students, they were given assignments to create a number of resources for K-12 students.

\subsection{Community Embedded Learning Model}

Candidate students used Young Adult books representing Native American cultures for book discussions with K-12 students. Area Native students located at the various hub site areas were utilized for participants in the book discussions. As well, Native students from the Cherokee Nation's Sequoyah High School and Oaks Indian School participated in book discussions. Resource bibliographies of recommended titles for use in school communities serving Native students were also developed for practicing school librarians. By using the community embedded learning model, student candidates were able to 'bring back' ideas, lessons, theories, and values gained from the university to the local community, alleviating the possibility of resistance to an "outsider" viewpoint. Additionally, a culturally-responsive teaching component embedded within the IMLS grant sought to encourage the student candidates to look beyond their immediate responses to situations and beyond easy answers to more fully explore issues of diversity within classrooms. This component helped offer a broader world-view for the students, and recognize the powerful role that culture plays in schools and communities.

\subsection{Intergenerational Programs}

Candidate students also took part in intergenerational singing and storytelling programs that brought skipped generations together to create learning and interactional opportunities through singing. First language speaking elders and children helped to teach parents their native tongue through these events. The intergenerational classes served as beautiful examples of curriculum and pedagogy that created opportunities for people to communicate and learn together within the context of relationship. It also provided educators with insights into how the curricula in such programs might expand participants' communication and identity options while helping to foster and support intergenerational relationships as well as cultural understanding.

\subsection{Learning from Authentic Literature}

True multicultural education promotes understanding and cooperation through the use of authentic literature. Educational materials provided in libraries and used in classrooms should be as authentic and accurate as possible. Guiding students toward asking questions and finding their own answers is vital. One helpful technique in this process is to expose students of a variety of ethnic groups and ages to authentic works of Native literature. Learning from authentic literature means not learning or perpetuating stereotypes. Literacy through themes that Native students understand can provide positive opportunities for increased educational success. Multimedia footage gathered from the Cherokee Heritage Canter's Indian Territory Days was edited and processed for cultural history education videos housed on the grant Facebook page. The Heritage Collection included footage on aspects of the Cherokee language, of bow making, of blacksmithing, and of storytelling. Video footage from the Cherokee Nation Sequoyah High School relating to the philosophy and history of the school was also incorporated. Grant staff attended a first annual regional 7th-8th grade stickball event at the Stillwell High School in the fall of 2013. Cherokee Nation representatives, NSU Cherokee Promise Scholars, and University of Arkansas students and administrators participated in the cultural event. Three Cherokee Promise Scholars and a professor were interviewed later in the month to provide additional perspectives on these cultural heritage/educational videos. Other venues where 
multimedia footage was gathered include: the Cherokee Art Market show, with National Treasure traditional weaver: footage of Will Rogers impersonator, Andy Hogan who serves as Historical Museum Guide at the Will Rogers Memorial Museum; footage from the Visiting Indigenous Scholars series Storytelling exhibit of "Native Words, Native Warriors" Comanche Code talkers, and Gayle Ross storyteller; footage of faculty describing a Native Dolls collection; footage gathered from the Chickasaw Cultural Heritage Center's 'Three Sister's Ceremony" event; and audio interviews of: Cherokee Immersion School curriculum developers; and Mr. Ron Graham, President of the Muskogee Creek Freedman, who discussed the history of Freedmen in Oklahoma's Muskogee Creek Nation. Teacher informational packets with accompanying lesson plans, Smart board activities and worksheets with quizzes, and a video summary based on the videos were added to the education repository.

Specific examples of supplemental learning resources completed include: seven templates of Smart Board activities (games for literacy and numeracy; poems and songs about culture; Camtasia products on how to modify templates for Smart Board games); 17 documents that comprise various lesson plans; 33 worksheet examples on topics supported by various videos produced; and two graphic e-novels. Five multi-media learner video project series pieces were developed; two additional projects included a video series from the Cherokee Nation Immersion School, and a "Diverse Voices of NSU" project; and additional multimedia footage (video, photographs) was developed from university hosted seminars, workshops and conferences. Using an updated project plan, an external team - The Center for Digital Archaeology - (CoDA) was contracted to develop the learning resources and multimedia teaching tools that would power the curriculum and provide the crucial outreach to K-12 teachers and their students. CoDA created an online content management system to house the curriculum, related media, and archive legacy data for the project. In the collaboration, a customized version of Mukurtu CMS was produced to ensure that the content would be shared in culturally appropriate ways.

\section{Conclusion}

Cultural, racial, economic and social diversity is the underlying theme that flows throughout the stated goals and outcomes achieved through this program. We believe that diverse communities can succeed and flourish together. Educational improvement begins as we transform ourselves as library leaders through education, reflection, and a moral imperative to construct vital changes that improve the condition of education. Our institution has a proud tradition of successfully serving Native American populations since it was founded as a Cherokee seminary in the Tahlequah, Oklahoma area over 100 years ago. Today, our university serves the highest percentage population (just under 33\%) of Native American students of any public higher education institution in the United States. The racial composition of faculty and staff of our institution mirrors the diversity within the student body. Fifteen percent of the faculty and staff are American Indian or Alaskan Native, representing a wide range of indigenous cultures. This educational program utilized the strengths and wisdom of our student body, its faculty, and its tribal partners to enhance diversity and cultural awareness in our communities.

The program helped us attain our vision of positive change in diversity and equality in education. Pre-service teachers' knowledge, skills and dispositions to promote technology proficiency and inclusive practice in a culturally responsive manner was paramount. As a result, graduates were better prepared to meet the daunting challenges of providing strong quality education and services to students in highly diverse and economically disadvantaged communities. Issues pertaining to race, ethnicity, tribe, and indigenous populations were focused on and improved. Research-based strategies that were developed and presented provided graduates with hands-on techniques that will help them narrow the achievement gap for under-resourced students. Further, it provided avenues for educators to develop programs and collections that are more culturally responsive to community needs and promote an increased level of intercultural understanding. This program also increased institutional capacity to train candidates, and advanced the state of the art of education, and library and information science by providing digital instructional tools for teaching information literacy concepts to K-12 students. This experience helped teachers become culturally sensitive to the diverse students of today's and tomorrow's classrooms.

By 1990 one out of four school aged children came from a home where English was not a primary language and one out of six was born outside of the United States (Diller \& Moule, 2005). The result is a cultural gap in many of the nation's schools as a growing number of educators struggle to better serve students from cultures other than their own in response to dramatic demographic changes that have created culturally diverse schools in many areas of the U.S. It is predicted that by 2030 half of all U.S. elementary school children will be children of color. Countries around the world are seeing similar statistics. The cultural gap between students and their teachers can be a factor in students' academic performance and contribute to achievement gaps among different student groups. Schools must be 
able to respond to such diversification and address the needs of a rapidly changing and increasingly complex society and student population base. More importantly, teachers need to be able to support student diversity and create a learning environment of understanding and empathy along with knowledge of subject matter, beginning teachers must also have an understanding of learners and their social context in order to help them succeed. Only by participating in experiential activities and actively engaging with the culture, can we expect to gain a deeper understanding of diverse cultures.

Student populations are more diverse than ever and culture plays a critical role in learning. Cultural competence leads to more effective teaching, and helps address student achievement gaps. The overall effect of providing culturally responsive teachers, developing appropriate library material selection policies, and identifying quality learning materials and resources to improve culturally sensitive learning environments for Native students is crucial for long-term positive impacts on retention and success. All information literacy products produced, educators trained, curriculum developed, research generated, and learning experiences offered served multiple purposes. They help reach parents and communities to develop an awareness of new technologies and their potential applications in socially and culturally inclusive education. They draw on technology to overcome social barriers. And they continue to guide, support and influence the profession well into the future.

\section{References}

[1] Mji A. and Makgato M. (2006) 'Factors Associated with High School Leaners Poor Performance: a Sspotlight on Mathematics and Physical Science', South African Journal of Education 26(2), pp. 253-266.

[2] Darling-Hammond, L., and Baratz-Snowden, J. "A Good Teacher in Every Classroom: Preparing the Highly Qualified Teachers Our Children Deserve", Educational Horizons, Winter 2007, pp. 111-132.

[3] Wright S. and Grenier M. (2009), 'Examining Effective Teaching Via a Social Constructivist Pedagogy: Case study', International Journal of Education 130 (2), pp.255-264.

[4] Sapire I. \& Reed Y., (2011) 'Collaborative Design and Use of Open Educational Resources: A Case Study of Mathematics Teacher Education Project in South Africa. Distance Education, 32(2), pp. 195-211.

[5] Ladson-Billings, G., (1995), Toward a Theory of Culturally Relevant Pedagogy, American Educational Research Journal, 32(3), pp. 465-491.

[6] Au, K. H., (1993) Literacy Instruction in Multicultural Settings, Harcourt Brace, New York.
[7] Ladson-Billings, G. (1994) The dreamkeepers: Successful Teachers of African American children, JosseyBass.

[8] Delpit, L. (1995) Other people's children: Cultural conflict in the classroom, New Press, New York..

[9] Irvine, J. J. (2003) Educating Teachers for Diversity: Seeing with a Cultural Eye. Teachers College Press, New York.

[10] Moll, L. \& Gonzalez, N. (2004) Engaging life: A funds-of-knowledge approach to multicultural education. In J. A. Banks \& C. A. M. Banks (Eds.), Handbook of research on multicultural education (2nd ed., pp. 699-715). Jossey-Bass, San Francisco.

[11] Niero, S. (2010) The light in their eyes: Creating Multicultural Learning Communities (10th anniversary ed.). Teachers College Press, New York.

[12] Heflin, B. R., and Barksdale-Ladd. M. A. (2001) African American children's literature that helps students find themselves: Selection guidelines for grades $\mathrm{K}-3$. Reading Teacher 54(8), pp. 810-819.

[13] Bell, Y. R., and Clark, T. R. (1998) Culturally relevant reading material as related to comprehension and recall in African American children. Journal of Black Psychology 24(4), pp. 455-475.

[14] Gangi, J. M. (2008) The Unbearable Whiteness of Literacy Instruction: Realizing the Implications of the Proficient Reader Research. Multicultural Review 17(1): $30-35$.

[15] Heflin, B. R., and Barksdale-Ladd. M. A. (2001) African American children's literature that helps students find themselves: Selection guidelines for grades K-3. Reading Teacher 54(8), pp. 810-819.

[16] Kea, C., Campbell-Whatley, G., and Richards, H. (2006) Becoming Culturally Responsive Educators: Rethinking Teacher Education Pedagogy. National Center for Culturally Responsive Educational Systems, Retrieved from http://www.nccrest.org/Briefs/Teacher_Ed_Brief.pdf (Access Date: 23 March 2016)

[17] Cochran-Smith, M. (2004) Walking the Road: Race, Diversity, and Social Justice in Teacher Education, Teachers College Press, New York.

[18] American Association of School Librarians. (2013). Empowering Learners : Guidelines for School Library Programs. Chicago: American Association of School Librarians. http://search.ebscohost.com/login.aspx?direct=t

[19] rue \&scope $=$ site $\& d b=$ nlebk $\& d b=$ nlabk $\& A N=631590$ (Access Date: 11 March, 2016).

[20] Luna, G., and Medina, C. (2007) Promising Practices and Challenges: E-advising Special Education Rural Graduate Students. Rural Special Education Quarterly, 26(4), pp. 21-26.

[21] Wenger, E., (1998) Communities of Practice: Learning, Meaning, and Identity, Cambridge University Press, Cambridge, MA.. 
[22] Yukawa, J. (2010) Communities of Practice for Blended Learning: Toward an Integrated Model for LIS Education, Journal of Education for Library and Information Science, 51(2), pp. 54-75.

[23] Dow, M. J. (2008) Implications of Social Presence for Online Learning: A Case Study of MLS Students. Journal of Education for Library \& Information Science, 49(4), pp. 231-242.

[24] Kazmer, M. M. (2005) Community-Embedded Learning. Library Quarterly 75(2), pp. 190-202.

[25] Leonard, D. C. (2002) Learning Theories A to Z., Greenwood, Westport, CT.

[26] Ruey, S. (2010) A Case Study of Constructivist Instructional Strategies for Adult Online Learning. British Journal of Educational Technology 41(5), pp. 706-720.

[27] McNally, M.D. (2004) Indigenous pedagogy in the classroom: A service learning model for discussion. American Indian Quarterly, 28(3/4), pp. 604-617.

[28] Sparks, S. (2000) Classroom and Curriculum Accommodations for Native American Students. Intervention in School \& Clinic, 35(5), pp. 259-263.

[29] Diller, J. V., and Moule, J. (2005) Cultural Competence: A Primer for Educators, Thomson/Wadsworth, Belmont, Calif. 